\title{
Osteomyelitis of the pelvic bones in patients with spinal cord injury: Is magnetic resonance useful for preoperative diagnosis?
} \author{
Luca $^{3}$ \\ ${ }^{1}$ Plastic Surgery, Cesena Hospital, Ausl Romagna, Italy \\ 2Division of Infectious Diseases, S.Orsola-Malpighi University Hospital, Bologna, Italy \\ 3Montecatone Rehabilitation Institute, Imola, Italy \\ ${ }^{4}$ Department of Orthopedics Surgery, S. Maria della Scaletta Hospital, Imola (Bo), Italy
}

Sgarzani Rossella ${ }^{*}$, Tedeschi Sara ${ }^{2}$, Fabio F Trapani ${ }^{2}$, Capirossi Rita ${ }^{3}$, Battilana Micaela ${ }^{3}$, Gaiani Luca ${ }^{4}$, Palmonari Massimo ${ }^{4}$ and Negosanti

\begin{abstract}
Aim of the study: We report a prospective, observational, single-centre study on adult patients with spinal cord injury (SCI) and pressure sores undergoing surgical debridement and reconstruction at Montecatone Rehabilitation Institute from July 2013 to January 2016. The aim is to assess usefulness of magnetic resonance (MR) in pre-operative diagnosis of osteomyelitis.

Materials and methods: All the patients underwent preoperative MRI each MRI was evaluated independently by two radiologists and the exam was considered positive for osteomyelitis only when the two radiologists agreed on the diagnosis. All the surgical procedures consisted of a wide debridement of soft and bony tissues and reconstruction: bone specimens were collected and sent for culture and histopathological evaluation. Results of MRI and histopathology were compared.

Results: 85 patients were included in the study. The two radiologists working independently agreed on the diagnosis of osteomyelitis in $96 \%$ of the cases. Pre-operative MRI was considered positive for osteomyelitis in 45 cases. According to histology, osteomyelitis was diagnosed in 40 patients. MRI findings and histology were concordant in $61 \%$ of cases; 19 false positive and 14 false negative cases were found. Sensitivity and specificity of MR in the diagnosis of osteomyelitis were $65 \%$ and $58 \%$ respectively, with a positive predictive value of $58 \%$ and a negative predictive value of $65 \%$.

Conclusion: In our cohort sensitivity, specificity, positive predictive value and negative predictive value of MR for the diagnosis of osteomyelitis in patients with $\mathrm{SCI}$ and pressure ulcers are lower than previously described. Our findings suggest that MRI cannot be considered a reliable diagnostic technique for the diagnosis of osteomyelitis. We can conclude that MRI is not indispensable pre-operatively in SCI patients with pressure sores, and that all the patient should undergo a wide soft and bony tissues debridement as if they were all affected by osteomyelitis. Histological diagnosis is useful to decide the timing of antimicrobial therapy, that should be planned based on the results of the surgical specimen culture. Further studies are needed to investigate this topic.
\end{abstract}

\section{Introduction}

Patients with spinal cord injuries (SCI) are at a high risk of developing pressure sores due to decreased mobility and lack of sensation, with a reported prevalence between $23 \%$ and $33 \%,[1,2]$. Lifetime risk is estimated between $25 \%$ and $85 \%, 3$ and an associated mortality between $7 \%$ and $8 \%$. [1-3]

Montecatone Rehabilitation Institute is rehabilitation hospital mainly dedicated to patients with spinal cord injuries, with approximately 120 admissions per year for patients affected by pressure sores. Since 2011 a multidisciplinary management of pressure ulcers has been implemented and a dedicated team of plastic surgeons is committed to surgical treatment of grade III-IV lesions.

Complex pressure sores frequently involve the underlying bony structures and may be associated to osteomyelitis. Physical examination is not reliable in the diagnoses of osteomyelitis. The gold standard for the definite diagnosis of osteomyelitis is histology of bone biopsy and the identification of the causative microorganism by tissue culture. [4]
Previous studies have analyzed the usefulness of Magnetic Resonance Imaging (MRI) in the evaluation of osteomyelitis. Patients with SCI and pressure sores represent a difficult subgroup due to the frequent presence of heterotopic ossification in the pelvic bones, wide open wounds, scars for previous wounds, acute and cronic infection of the soft tissues.

In literature MRI for the diagnosis of osteomyelitis presents a sensitivity between $82 \%$ and $100 \%$ and a specificity between $75 \%$ and $96 \%$, especially in the long bones. [5]

The objective of our study is to assess usefulness of magnetic resonance (MR) in pre-operative diagnosis of osteomyelits of the pelvis in patients with spinal cord injury (SCI) and pressure ulcers.

${ }^{\star}$ Correspondence to: Rossella Sgarzani, Ospedale Maurizio Bufalini, viale Ghirotti 286, 47521 Cesena, Italy, Tel: 00393395384929; E-mail: rossellasgarzani@libero.it

Key words: pressure sores, MRI, osteomyelitis

Received: June 17, 2019; Accepted: July 10, 2019; Published: July 17, 2019 


\section{Materials and methods}

We present a prospective, observational, single-centre study on adult (age $\geq 18$ years) patients with spinal cord injury (SCI) undergoing surgical debridement and reconstruction for pressure ulcer of the pelvis (ischium or sacrum) at Montecatone Rehabilitation Institute from July 2013 to January 2016 (Table 1).

All patients included in the study underwent MRI study of the body part affected by pressure ulcer, during the 30 days before the scheduled surgery. Each MRI was evaluated independently by two radiologists, the two radiologists were blinded to each other. According to MRI findings, a diagnosis of osteomyelitis was established in presence of two or more of the following: i) cortical bone erosion, ii) abnormal signal of the marrow on T1-weighted and STIR images, iii) soft-tissue edema, iv) deep collections, v) heterotopic new bone, vi) hip effusion.

MRI was considered positive for osteomyelitis only when the two radiologists agreed on the diagnosis.

Surgical intervention was performed within 30 days from MRI, by the same surgical equipe. All the patients underwent surgical wide debridement of soft and bony tissue. The reconstruction was performed by local fasciocutaneous or musculo-cutaneous flaps.

During surgery, multiple bone and soft tissue specimens were collected and sent for culture and histopathological evaluation (at least 3 per type of tissue). Histopathological and culture analysis were performed in a single lab. The histopathological results of bony intraoperative specimens were regarded as the reference for the definitive diagnosis of osteomyelitis and were compared to MRI results.

Collected data included: demographics of the patient (age, sex); comorbidities (diabetes, venous thrombosis, solid tumour, renal failure); level and cause of spinal cord injury; site and stage of the pressure ulcer (assessed according to the European Pressure Ulcer Advisory Panel classification); MRI findings; results of histopathology of bone intra-operative samples.

\section{Statistical analysis}

Descriptive statistics were obtained for all the variables assessed in the study population. Mean and standard deviation were used for normally distributed continuous variables, median and interquartile range for skewed distributions, proportions for categorical variables. MRI results were compared with histopathology of intra-operative bone biopsy, that represent the gold standard for diagnosis of osteomyelitis. Sensitivity, specificity positive and negative predictive value of MRI in diagnosing osteomyelitis were calculated. Analysis were performed with SPSS 20.0.

\section{Results}

During study period 85 patients were included in the study: $89 \%$ were males, median age was 48 years (IQR 36-63); 61 patients (72\%) were paraplegic and 24 quadriplegics. Etiology of spinal cord injury was trauma in the majority of them (86\%).

Pressure ulcers involved ischium in $58,8 \%$, sacrum in $32.9 \%, 7$ patients $(8.2 \%)$ had ulcers in multiple sites.

Stage of lesion was IV in $79 \%$ of patients, III in $13 \%$ and in 7 cases (8\%) lesion was deemed unstageable.

The two radiologists working independently and blinded to each other agreed on the diagnosis of osteomyelitis in $96 \%$ of the cases, which were considered positive for osteomyelitis.

According to pre-operative MR osteomyelitis was diagnosed in 45 cases. According to histopathology a definite diagnosis of osteomyelitis was performed in 40 patients.

According to intraoperative specimen cultures, the most common micro-organisms were Staphylococcus aureus $(41,8 \%$ of the positive specimens), Proteus mirabilis ( $34,1 \%$ of the positive specimens), and Pseudomonas aeruginosa (16,5\% of the positive specimens).

When compared to each other, MRI and histopathology findings were concordant in $61 \%$ of cases (52/85); 19 false positive (MR positive/ histology negative) and 14 false negative (MR negative/histology positive) were found.

Sensitivity and specificity of MR in the diagnosis of osteomyelitis were $65 \%$ and $58 \%$, respectively, with a positive predictive value of $58 \%$ and a negative predictive value of $65 \%$.

Table 1. Demographic and clinical characteristics of the study population and comparison between patients with and without osteomyelitis

\begin{tabular}{|c|c|c|c|c|}
\hline & All patients $(n=85)$ & $\begin{array}{l}\text { Patients without osteomyelitis } \\
\qquad(n=45)\end{array}$ & Patients with osteomyelitis $(n=40)$ & $\mathbf{p}$ \\
\hline Age (ys)-median (IQR) & $48(36-63)$ & $44(26-61)$ & $54(42-65)$ & 0.045 \\
\hline Male sex- $n^{\circ}(\%)$ & $76(89)$ & $40(90)$ & $36(90)$ & 0.868 \\
\hline $\begin{array}{l}\text { Level of SCI-n }{ }^{\circ}(\%) \\
\text { Paraplegia } \\
\text { Quadriplegia }\end{array}$ & $\begin{array}{l}61(72) \\
24(28)\end{array}$ & $\begin{array}{l}32(71) \\
13(29)\end{array}$ & $\begin{array}{l}29(72) \\
11(27)\end{array}$ & 0.565 \\
\hline $\begin{array}{l}\text { Etiology of SCI-n }{ }^{\circ}(\%) \\
\text { Trauma } \\
\text { Vascular } \\
\text { Other }\end{array}$ & $\begin{array}{c}73(89) \\
5(6) \\
7(5)\end{array}$ & $\begin{array}{l}39(87) \\
2(4.4) \\
4(8.6)\end{array}$ & $\begin{array}{l}34(85) \\
3(7.5) \\
3(7.5)\end{array}$ & 0.930 \\
\hline $\begin{array}{l}\text { Comorbidities-n }{ }^{\circ}(\%) \\
\text { Diabetes } \\
\text { Venous thrombosis } \\
\text { Solid tumour } \\
\text { Renal failure }\end{array}$ & $\begin{array}{l}11(13) \\
7(8.2) \\
5(6) \\
2(2.4)\end{array}$ & $\begin{array}{l}4(9) \\
1(2.2) \\
3(7) \\
0(0)\end{array}$ & $\begin{array}{l}7(17.5) \\
6(15) \\
2(5) \\
2(5)\end{array}$ & 0.152 \\
\hline $\begin{array}{l}\text { Site of pressure ulcer-n }{ }^{\circ}(\%) \\
\text { Ischium } \\
\text { Sacrum } \\
\text { Multiple }\end{array}$ & $\begin{array}{c}50(58.8) \\
28(32.9) \\
7(8.2)\end{array}$ & $\begin{array}{c}14(16.4) \\
16(18.8) \\
3(3.5)\end{array}$ & $\begin{array}{c}36(42.3) \\
12(14.11) \\
4(4.7)\end{array}$ & 0.064 \\
\hline $\begin{array}{l}\text { Stage of pressure ulcer-n }{ }^{\circ}(\%) \\
\text { III } \\
\text { IV } \\
\text { Unstageable }\end{array}$ & $\begin{array}{c}11(13) \\
67(79) \\
7(8)\end{array}$ & $\begin{array}{c}8(18) \\
33(73) \\
4(9)\end{array}$ & $\begin{array}{l}3(7.5) \\
34(85) \\
3(7.5)\end{array}$ & 0.299 \\
\hline
\end{tabular}




\section{Discussion}

Pressure sores in SCI patients cause significant morbidity and are difficult to treat, particularly in case of osteomyelitis. In this study we investigate a single cohort of patients with SCI and pressure sore with potential osteomyelitis because SCI patients with high degree pressure sore, differently to non-SCI patients, always have surgical indication in order to allow the patient a social life.

Any pressure sore can be complicated by osteomyelitis, osteomyelitis can not be diagnosed clinically, in fact signs of infection can be due to soft tissue infection. Current imaging modalities employed in pressure sores with suspect osteomyelitis include ultrasound, ostheoscintygraphy, plain films, computed tomography (CT), MRI and PET [6-16]. Ultrasound is not helpful for visualizing bone changes associated with osteomyelitis, nor can it detect associated surrounding soft-tissue infection, but it can be useful to detect fluid collection in joints or soft tissue. Ostheoscintygraphy is reliable in excluding bony infection [14,15], but it is not specific for the diagnosis of osteomyelitis in presence of soft-tissues infection, orthopedic devices, trauma, healing fractures, arthritis, surgery, or diabetes [17].

$\mathrm{CT}$ and plain films require the use of radiation and are limited in their ability to predominantly show bone changes. Often an irregularity of bone surface is due to erosion, but the cause of erosion is impossible to determine (trauma, neoplasia, exposure, infection, poor vascularity). The overall reported sensitivity of CT and plain film to detect osteomyelitis is $61 \%$ and the specificity is up to $69 \%$.[18]

PET is not available in all the hospitals and is very expensive, it is useful to detect infection but in the clinical practice it is usually not applied to SCI patients with ulcers. [19]

MRI has been recognized for its exceptional soft tissue bone marrow contrast resolution and multiplanar capability, which offers greater anatomical detail than CT or conventional plain films [19]. The sensitivity of MRI for the diagnosis of osteomyelitis has been reported between $82 \%$ and $100 \%$, and specificity between $75 \%$ and $96 \%$. [20]

Hencey in 1996 studied 37 male SCI patients for a total of 44 diagnostic and concluded that MRI is helpful in determining the depth and extent of soft tissue involvement underlying decubitus ulcers, and beneficial in planning proper therapy [21].

Huang performed 59 MR examinations in 44 paralyzed patients with clinically suspected acutely active osteomyelitis. 49 fulfilled the criteria for the diagnosis of osteomyelitis. Osteomyelitis was excluded by histologic results in 3 patients and clinical follow-up in 5 patients. The overall accuracy of MRI was $97 \%$ with a sensitivity $98 \%$ and specificity of $89 \%$. [22]

In 2012 Lopez analyzed 37 patients with SCI underwent 41 MRI scan and reported a significant association between the prevalence of osteomyelitis and cortical bone erosion and abnormal marrow edema in T1-weighted scan. While deep collections, heterotopic new bone formation, and hip effusion were not of significant predictive value in assessing the risk of osteomyelitis. [13]

Previous studies show that MRI is useful in the diagnosis and monitoring of osteomyelitis. These studies state that MRI is able to diagnose the associated findings in spinal cord-injured patients, including fistulous tract, fluid collections, abscesses, and extent of ulcer and assessed that can guide surgeons for the resection [23-30].

In 2016 Brunel reported a poor agreement between biopsies and MRI ( $\kappa 0.2)$ [31]. In our series sensitivity and specificity of MRI was not high, respectively $65 \%$ and $58 \%$. We also reported an high negative predictive value of $65 \%$ and a positive predictive value of $58 \%$. Considering these findings we believe that MRI is not useful in diagnosis and monitoring of osteomyelitis. In our experience MRI seems to be not cost-effective considering the higher costs of the exam, the limited availability, the risks linked to the use of contrast and the reported low accuracy of the results. The small sample size of our cohort and the single center design of the present study are a limitation of the study, in fact they may limit the possibility to generalize results due to possible bias. On the other hand the rduced inter-observer variability of the two blinded radiologists can be considered a strength of the study. As the knowledge in the field of diagnostic performance of MRI to identify osteomyelitis in SCI patients with pressure ulcers is limited, the study can provide useful information for clinical practice. In our opinion in SCI patients affected by pressure sores multiple bone biopsies are mandatory to have a microbiological and histological report, that is the gold standard for the diagnosis of osteomyelitis and allows to administer the correct antibiotic therapy (in terms of medications and time) and to plan a proper follow up (of the wound and blood tests). The bony surgical resection should always be wide (to treat eventual osteomyelitis), and only vital non exposed bone should be preserved.

Our results compare with the retrospective analysis reported by McCarthy in 2017 on 152 patients with pressure ulcer: test properties of MRI for diagnosis of osteomyelitis in patients with chronic pressure ulcers have limited ability to diagnose osteomyelitis and do not aid in surgical management, but do increase health-care expense. [32]

Recently Diffusion Weighted Magnetic Resonance Imaging [3335 ] has been introduced as a new tool used not only to differentiate benign from malignant skeletal lesions, but also to detect osteomyelitis. This method seems to be promising, but on the other hand more is needed to evaluate whether a preoperative diagnosis of osteomyelitis may improve the final surgical outcome.

\section{Conclusion}

Based on our results MRI cannot be regarded as a reliable technique for the diagnosis of osteomyelitis in patients with SCI and pressure ulcers, all the patient should undergo a wide soft and bony tissues debridement as they were all affected by osteomyelitis. Further studies are needed to investigate this topic.

\section{Conflicts of interest}

None.

\section{References}

1. Reuler JB, Cooney TG (1981) The pressure sore: pathophysiology and principles of management. Ann Intern Med 94: 661-666. [Crossref]

2. Richardson RR, Meyer PR Jr (1981) Prevalence and incidence of pressure sores in acute spinal cord injuries. Paraplegia 19: 235-247. [Crossref]

3. Dinsdale SM (1974) Decubitus ulcers: role of pressure and friction in causation. Arch Phys Med Rehabil 55: 147-152. [Crossref]

4. White LM, Schweitzer ME, Deely DM, Gannon F (1995) Study of osteomyelitis: utility of combined histologic and microbiologic evaluation of percutaneous biopsy samples. Radiology 197: 840-842.

5. Santiago Restrepo C, Gimenez CR, McCarthy K (2003) Imaging of osteomyelitis and musculoskeletal soft tissue infections: current concepts. Rheum Dis Clin North Am 29: 89-109.

6. Borgström PS, Ekberg O, Lasson A (1988) Radiography of pressure ulcers. Acta Radiol 29: 581-584. [Crossref]

7. Hendrix RW, Calenoff L, Lederman RB, Nieman HL (1981) Radiology of pressure sores. Radiology 138: 351-356. [Crossref] 
8. Lewis VL Jr, Bailey MH, Pulawski G, Kind G, Bashioum RW, et al. (1988) The diagnosis of osteomyelitis in patients with pressure sores. Plast Reconstr Surg 81: 229232. [Crossref]

9. Lisbona R, Rosenthall L (1997) Observations on the sequential use of 99m-Tc phosphate complex and 67-Ga imaging in osteomyelitis, cellulitis, and septic arthritis. Radiology 123: 123-129.

10. Jacobson AF, Harley JD, Lipsky BA, Pecoraro RE (1991) Diagnosis of osteomyelitis in the presence of soft-tissue infection and radiologic evidence of osseous abnormalities: value of leukocyte scintigraphy. AJR Am J Roentgenol 157: 807-812. [Crossref]

11. Esposito G, Ziccardi P, Meoli S, Rengo C, Scioli M, et al. (1994) Multiple CT imaging in pressure sores. Plast Reconstr Surg 94: 333-342. [Crossref]

12. Firooznia H, Rafii M, Golimbu C, Sokolow J (1983) Computerized tomography of pelvic osteomyelitis in patients with spinal cord injuries. Clin Orthop Relat Res 5: 126131. [Crossref]

13. López de Heredia L, Hauptfleisch J, Hughes R, Graham A, Meagher TMM (2012) Magnetic resonance imaging of pressure sores in spinal cord injured patients: accuracy in predicting osteomyelitis. Top Spinal Cord Inj Rehabil 18: 146-148.

14. Howie DW, Savage JP, Wilson TG, Paterson D (1983) The technetium phosphate bone scan in the diagnosis of osteomyelitis in childhood. J Bone Joint Surg Am 65: 431-437. [Crossref]

15. Schauwecker DS (1992) The scintigraphic diagnosis of osteomyelitis. AJR Am J Roentgenol 158: 9-18. [Crossref]

16. Expert Panel on Musculoskeletal Imaging, Beaman FD, von Herrmann PF, Kransdorf MJ, Adler RS, Amini B, et al. (2017) ACR appropriateness criteria ${ }^{\circledR}$ suspected osteomyelitis, septic arthritis, or soft tissue infection excluding spine and diabetic foot. J Am Coll Radiol 14: S326-S337. [Crossref]

17. Haliloglu M, Kleiman MB, Siddiqui AR, Cohen MD (1994) Osteomyelitis and pyogenic infection of the sacroiliac joint. MRI findings and review. Pediatr Radiol 24: 333-335.

18. Larson DL, Gilstrap J, Simonelic K, Carrera GF (2011) Is there a simple, definitive, and cost-effective way to diagnose osteomyelitis in the pressure ulcer patient? Plast Reconstr Surg 127: 670-676.

19. Chaundhry AA, Gul M, Gould E, Teng M, Baker K, et al. (2016) Utility of positron emission tomography-magnetic resonance imaging in musculoskeletal imaging. World J Radiol 8: 268-274.

20. Sammak B, Abd El Bagi M, Al Shahed M, Hamilton D, Al Nabulsi J, et al. (1999) Osteomyelitis: a review of currently used imaging techniques. Eur Radiol 9: 894-900. [Crossref]

21. Hencey JY, Vermes M, Van Geertruyden HH, Binard JE, Manchepalli S (1996) Magnetic resonance imaging examinations of gluteal decubitus ulcers in spinal cord injury patients. J Spinal Cord Med 19: 5-8.
22. Huang AB, Schweitzer ME, Hume E, Batte WG (1998) Osteomyelitis of the pelvis/hips in paralyzed patients: accuracy and clinical utility of MRI. J Comput Assist Tomogr 22: $437-443$.

23. Berquist TH, Brown ML, Fitzgerald RH Jr, May GR (1985) Magnetic resonance imaging application in musculoskeletal infection. J Magn Res Imag 3: 219-230.

24. Beltran J, Noto AM, McGhee RB, Freedy RM, McCalla MS (1987) Infections of the musculoskeletal system: high-field-strength MR imaging. Radiology 164: 449-454.

25. Tang JSH, Gold RH, Bassett LW, Seeger LL (1988) Musculoskeletal infection of the extremities: evaluation with MR imaging. Radiology 166: 205-209.

26. Beltran J, McGhee RB, Shaffer PB (1988) Experimental infections of the musculoskeletal system: evaluation with MR imaging and Tc-99m MDP and Ga-67 scintigraphy. Radiology 167: 167-72.

27. Quinn SF, Murray W, Clark RA, Cochran C (1988) MR imaging of chronic osteomyelitis. J Comput Assist Tomogr 12: 113-117. [Crossref]

28. Erdman WA, Tamburro F, Jayson HT, Weatherall PT, Ferry KB, et al. (1991) Osteomyelitis: characteristics and pitfalls of diagnosis with MR imaging. Radiology 180: 533-539. [Crossref]

29. Weinstein D, Wang A, Chambers R, Stewart CA, Motz HA (1993) Evaluation of magnetic resonance imaging in the diagnosis of osteomyelitis in diabetic foot infections. Foot Ankle 14: 18-22. [Crossref]

30. Morrison WB, Schweitzer ME, Wapner KL, Hecht PJ, Gannon FH, et al. (1995) Osteomyelitis in feet of diabetics: clinical accuracy, surgical utility, and costeffectiveness of MR imaging. Radiology 196: 557-564. [Crossref]

31. Brunel AS, Lamy B, Cyteval C, Perrochia H, Téot L, et al. (2016) OSTEAR Study Group. Diagnosing pelvic osteomyelitis beneath pressure ulcers in spinal cord injured patients: a prospective study. Clin Microbiol Infect 22: 267.e1-8.

32. McCarthy J, Hartmann E, Bentz ML, Rao VK, Jee Y, et al. (2017) Seeing is believing? preoperative magnetic resonance imaging for pressure ulcers: implications for surgical management. Plast Reconstr Surg Glob Open 5: e1263.

33. Douis H, Davies MA, Sian P (2016) The role of diffusion-weighted MRI (DWI) in the differentiation of benign from malignant skeletal lesions of the pelvis. Eur J Radiol 85: 2262-2268. [Crossref]

34. Eren MA, Karakas E, Torun AN, Sabuncu T (2018) The clinical value of diffusion weighted magnetic resonance imaging in diabetic foot infection. $J$ Am Podiatr Med Assoc. 2: 1-5.

35. Leclair N, Thörmer G, Sorge I, Ritter L, Schuster V, et al. (2016) Whole-body diffusionweighted imaging in chronic recurrent multifocal osteomyelitis in children. PLoS One 11: e0147523.

Copyright: (C2019 Rossella S. This is an open-access article distributed under the terms of the Creative Commons Attribution License, which permits unrestricted use, distribution, and reproduction in any medium, provided the original author and source are credited. 